\title{
Degradation of the plant cell wall by nematodes
}

\author{
Eric L. Davis ${ }^{1}$, Annelies Haegeman ${ }^{2}$, and Taisei Kikuchi ${ }^{3}$
}

${ }^{1}$ Department of Plant Pathology, North Carolina State University, Raleigh, NC 27695 USA

${ }^{2}$ Department of Molecular Biotechnology, Ghent University, B-9000 Ghent, Belgium

${ }^{3}$ Forestry and Forest Products Research Institute, Tsukuba, Ibaraki 305-8687, Japan

1) Intro

2) Enzymatic degradation of plant cell walls

2.1) cellulose

2.2) hemicellulose

2.3) pectin

3) Non-enzymatic modification of plant cell walls

4) Degradation of fungal cell walls

5) Evolutionary relationships

6) Concluding remarks

\section{$\underline{\text { Abstract }}$}

Evidence from as early as the 1950's that phytoparasitic nematodes could secrete enzymes to facilitate penetration of the stylet through the host cell wall or to promote nematode migration within plant tissues was confirmed in 1998 with the report of the first genes encoding endogenous endo-1,4- $\beta$-glucanases isolated from animals, the phytoparasitic cyst nematodes. Expressed gene analyses and recent genome sequencing efforts have since identified genes encoding cellulases, hemicellulases, pectinases, and chitinases in multiple species of phytoparasitic nematodes. A cellulose-binding motif present in some nematode endoglucanases also exists independently of the hydrolytic domain in some species and has promoted the discovery of the first expansins outside of the plant kingdom. Database homologies and phylogenetic analyses suggest the potential for independent ancient horizontal gene transfer events of genes encoding a number of nematode cell wall-modifying proteins from microbes present in the nematode's ecological niche, including soil bacterial sources for root-feeding nematodes and fungal sources for shoot and fungal-feeding nematodes. Subsequent gene duplication and domain shuffling activity has apparently led to the evolutionary expansion of families of genes encoding cell wall-modifying proteins within nematode genomes. In almost all cases, expression of these cell wall-modifying proteins is restricted and active in the nematode esophageal gland cells for secretion from the stylet during migratory stages of the nematode parasitic cycle.

Key words: cellulase, chitinase, esophageal gland cells, expansin, fungal cell wall, horizontal gene transfer, pectinase, plant cell wall, secretions, xylanase

\section{0) Introduction}

The plant cell wall represents a formidable barrier to ectoparasitic nematodes that feed from outside of plant tissues as well as to endoparasitic nematodes that must penetrate, migrate, and feed within host plant tissues. The plant cell wall is a thick, rigid structure formed from an extensive network of cellulose microfibrils, hemicelluloses, pectins, and proteins that all undergo regulated changes in architecture during normal plant growth and development (Carpita and Gibeaut, 1993). Two types of cell walls can be distinguished in plants -- the 
primary wall, which surrounds actively growing cells, and the secondary wall, which is deposited as the plant cell matures. Primary walls are deposited during cell growth, and need to be both mechanically stable and sufficiently extensible to permit cell expansion while avoiding the rupture of cells under turgor pressure. Primary cell walls consist mainly of polysaccharides that can be broadly classified as cellulose, the cellulose-binding hemicelluloses, and pectins. Secondary cell walls are deposited after the cessation of cell growth and confer mechanical stability upon specialized cell types such as xylem elements and sclerenchyma cells. These walls represent composites of cellulose and hemicelluloses, and are often impregnated with lignins. In addition to polysaccharides, plant cell walls contain hundreds of different proteins. Many of these proteins are considered to be 'structural' proteins (Cassab, 1998), whereas others participate in cell wall remodeling and turnover (Darley et al., 2001).

The sclerotized, protrusible stylet of phytoparasitic nematodes provides a tool to mechanically breach the host plant cell wall. Such stylet activity can be readily observed for nematodes grown in monoxenic plant root culture and has been documented for both ectoparasitic and endoparasitic nematodes in video microscopy (Wyss, 1987; Wyss and Zunke, 1986; Wyss et al., 1992). An early body of evidence suggested that nematodes also secrete hydrolytic cell wall-degrading enzymes to assist in this process (reviewed in Deubert and Rohde, 1971). Protein extracts and exudates from a number of phytoparasitic and fungal-feeding nematode species contained cellulolytic, amylolytic, chitinolytic, and pectolytic enzyme activity, suggesting the potential for endogenous production and secretion of cell wall-degrading enzymes from nematodes. Since the nematodes that were analyzed for this enzyme activity were reared on plant tissues and sometimes recovered non-aseptically, the true origins of the cell wall-degrading enzymes remained in question.

As studies of the proteins synthesized in the esophageal gland cells and secreted through the stylet of tylenchid phytoparasitic nematodes (Hussey, 1989) began to incorporate the developing tools of molecular biology, the first confirmation of cell wall-degrading enzymes of nematode origin emerged (Smant et al., 1998). Amino acid sequence of cyst nematode proteins that were affinity-purified by a gland-specific monoclonal antibody (De Boer et al., 1996) was used to derive the first endogenous coding sequence of beta-1,4-endoglucanase genes isolated from any animal (Smant et al., 1998). Even more remarkable was the similarity of the cyst nematode endoglucanases to bacterial members of glycosyl hydrolase (GH) family 5 (Henrissat and Bairoch, 1996), providing some of the first evidence of potential horizontal gene transfer (HGT) from prokaryotes to eukaryotes (Davis et al., 2000; Keen and Roberts, 1998; Smant et al., 1998; Yan et al., 1998). Complementary studies on the developmental expression patterns of the isolated cyst nematode endoglucanase genes associated endoglucanase expression with the migratory life stages of cyst nematodes (De Boer et al., 1999; Goellner et al. 2000), including re-deployment of endoglucanase expression specifically within cyst nematode males that re-gain motility later in development. Immunolocalization of secreted cyst nematode endoglucanases along the migratory path of cyst juveniles within plant root sections provided the first definitive evidence of in planta secretion of proteins derived from the esophageal gland cells of phytonematodes (Wang et al., 1999).

Endoglucanase genes in a number of other phytoparasitic nematode species have subsequently been identified (see Davis et al., 2009; Kyndt et al., 2008; Mitchum et al., 2007) since the 1998 Smant et al report. The carbohydrate-binding motif (CBM) present in some phytoparasitic nematode endoglucanases also exists in the absence of an endoglucanase active site, leading to the isolation of a number of non-enzymatic cell wall-modifying proteins from 
nematodes (see Davis et al., 2009; Kikuchi et al., 2009; Kyndt et al., 2008; Mitchum et al., 2007). Candidate gene approaches and differential gene expression analyses in phytoparasitic nematodes have also identified genes encoding a number of different pectolytic and hemicellulolytic enzymes (see Davis et al., 2009; Mitchum et al., 2007) that would provide the ability to degrade other complex carbohydrate components of the plant cell middle lamella and wall. In phytoparasitic nematodes and related species that have adapted to feed on fungi, genes encoding enzymes with the potential ability to modify the plant and fungal cell wall have also been identified (Jones et al., 2005, 2008; Kikuchi et al., 2004, 2005, 2007). The growing number of genes encoding cell wall-modifying proteins that have been isolated from phytoparasitic nematodes, fungal feeders, and even non-parasitic nematode species has provided a framework for discussions on their evolutionary mechanisms and origins (Baldwin, et al., 2004; Davis et al., 2000; Dieterich and Sommer, 2009; Haegeman et al., 2010; Hotopp et al., 2007; Jones et al., 2005; Kyndt et al., 2008; Ledger et al., 2006; Mitreva et al., 2009; Scholl et al., 2003; Wasmuth et al., 2008).

\section{0) Enzymatic degradation of plant cell walls}

\section{1) Cellulose}

The key structural component of the plant cell wall is cellulose, the most abundant biopolymer in the world. Cellulose is composed of successive glucose residues which are inverted $180^{\circ}$, forming a flat ribbon with cellobiose as the repeating unit (Taylor, 2008). These $(1,4)-\beta$-linked glucan chains are able to form extensive hydrogen bounds to adjacent glucan chains (Somerville, 2006). Approximately 36 of these crystalline chains are arranged in parallel in $3 \mathrm{~nm}$ thick microfibrils forming insoluble cable-like structures. Cellulose microfibrils are among the longest molecules known in nature, since they are believed to consist of 8000 (primary cell wall) to 15,000 (secondary cell wall) glucose molecules (Somerville, 2006).

Glycoside hydrolases are enzymes that catalyze the hydrolysis of the glycosidic bonds in sugar polymers. These glycosyl hydrolases are classified into different families according to their sequence similarity (Henrissat and Bairoch, 1996). Cellulases or endo-1,4- $\beta$-glucanases for example are capable of degrading cellulose by hydrolyzing the (1,4)- $\beta$ bonds. Several endoglucanases (or cellulases, EC 3.2.1.4) belonging to different glycosyl hydrolase families have been found in nematodes, facilitating the penetration and migration of the nematode through the plant cell wall.

Most of the identified endoglucanases in nematodes belong to glycosyl hydrolase family 5 (GHF5). GHF5 endoglucanases were found in several nematodes belonging to the superfamily of the Tylenchoidea (order Rhabditida, suborder Tylenchina, infraorder Tylenchomorpha) (De Ley and Blaxter, 2002). The majority belongs the well studied sedentary nematode genera Heterodera, Globodera and Meloidogyne (Abad et al., 2008; Bera-Maillet et al., 2000; Gao et al., 2002a; Gao et al., 2004a; Goellner et al., 2000; Ledger et al., 2006; Rehman et al., 2009; Rosso et al., 1999; Smant et al., 1998; Yan et al., 2001). Besides these sedentary nematodes, GHF5 endoglucanases have also been identified in the migratory nematodes Radopholus similis, Ditylenchus africanus and Pratylenchus species (Haegeman et al., 2008; Kyndt et al., 2008; Uehara et al., 2001). The GHF5 endoglucanases consist of several domains. They all have a signal peptide, which is required to secrete the protein, and a catalytic domain with the actual enzyme activity. Some endoglucanase have an 
additional carbohydrate binding module (CBM) at the C-terminal end of the protein, which is thought to aid the enzyme in the binding to its substrate (Boraston et al., 2004).

Interestingly, GHF45 endoglucanases have been cloned (Kikuchi et al., 2004) from Bursaphelenchus xylophilus (Aphelenchoidea superfamily). The different glycosyl hydrolase family suggests a different origin for endoglucanases in the Aphelenchoidea. Nevertheless, within the Aphelenchoidea a GHF5 endoglucanase has also been identified in the fungivorous nematode Aphelenchus avenae (Karim et al., 2009). It should however be noted that the taxonomic position of this nematode is being questioned and recent evolutionary trees suggest that it is more related to the Tylenchoidea instead of the Aphelenchoidea (van Megen et al., 2009).

Not much is known for phytoparasitic nematodes which belong to the Dorylaimida and Triplonchida orders. Only one dorylaimid nematode, Xiphinema index, was shown to posses GHF12 endoglucanases (Jones et al., 2005). The fact that yet another glycosyl hydrolase family is involved, confirms the independent origin of plant parasitism within nematodes (Blaxter et al., 1998).

\section{2) Hemicellulose}

Cellulose microfibrils are embedded in a matrix of complex polysaccharides, which are divided into two classes: pectins and hemicellulose. Hemicelluloses are cellulose binding polysaccharides that form a strong but resilient network together with the cellulose. More specifically, they are defined as carbohydrate polymers of either xylose, glucose, mannose or mannose and glucose joined mainly by (1,4)- $\beta$ and (1,3)- $\beta$ glycosidic bonds (Bacic et al., 1988). The major component of hemicellulose is xylan, the second most abundant polysaccharide in nature. Xylan is composed of $(1,4)$ - $\beta$-linked xylopyranose units and can have various substituents and variable structures according to the plant species (Collins et al., $2005)$. Other components of hemicellulose, such as lichenan, contain both $(1,3)-\beta$ and $(1,4)-\beta$ linkages (Bacic et al., 1988).

Nematode GHF5 endoglucanases can show activity against hemicelluloses, but the activity seems limited to $(1,4)-\beta$ linked polysaccharides (Gao et al., 2004b). The GHF45 endoglucanases of B. xylophilus are also active against glucomannan (Shibuya and Kikuchi, 2008). A limited activity of some endoglucanases against lichenan has also been observed (Bera-Maillet et al., 2000; Gao et al., 2004b; Shibuya and Kikuchi, 2008). Some endoglucanases are able to hydrolyze xylan, as demonstrated for endoglucanases of Heterodera glycines (Gao et al., 2004b). In addition, specific endoxylanase enzymes have been identified in a limited number of nematodes: in Meloidogyne species and in Radopholus similis (Abad et al., 2008; Haegeman et al., 2009a; Mitreva-Dautova et al., 2006; Opperman et al., 2008). These xylanases belong to a glycosyl hydrolase family situated between GHF5 and GHF30 and have a domain structure similar to the endoglucanases: a signal peptide, a catalytic domain and in some cases a C-terminal CBM (Haegeman et al., 2009a).

\section{3) Pectin}

Pectin is a major structural component of the plant cell wall, along with cellulose and hemicellulose. Pectin is located mainly in the middle lamella and primary cell wall and functions as a matrix anchoring the cellulose and hemicellulose fibers (Carpita and Gibeaut, 1993). The breakdown of pectin leads to the maceration of plant tissues, the characteristic 
symptom of soft-rot diseases (Lietzke et al., 1994). Pectin degradation requires the combined action of several enzymes. These can be divided into two groups: pectin esterases, which remove the methoxyl groups from pectin, and depolymerases (hydrolases and lyases), which cleave the backbone chain (Tamaru and Doi, 2001). Phytoparasitic nematodes possess two types of depolymerase for pectin degradation: pectate lyase and polygalacturonase. No pectin esterase has been reported from phytoparasitic nematodes.

\section{a) Pectate lyase}

Pectate lyase (pectate transeliminase, EC 4.2.2.2), which catalyzes the cleavage of the internal $\alpha-1,4$-linkages of unesterified polygalacturonate (pectate) by $ß$-elimination, plays a critical role in pectin degradation (Barras et al., 1994). Pectate lyases are distributed widely among bacterial and fungal plant pathogens and have been the focus of several studies that have examined their function as virulence factors (Barras et al., 1994). They are used by plant pathogens to degrade host cell walls to allow penetration and colonisation.

Genes encoding pectate lyases have been cloned from several sedentary phytoparasitic nematodes, including species of Heterodera, Globodera, and Meloidogyne (Popeijus et al., 2000; de Boer et al., 2002; Doyle and Lambert, 2002; Huang et al., 2005; Kudla et al., 2007; Vanholme et al., 2007), and the migratory phytoparasitic nematode Bursaphelenchus xylophilus (Kikuchi et al., 2006). These pectate lyases are produced in the esophageal gland cells and are secreted from the stylet of the nematode. Together with cellulases and hemicellulases, the pectate lyases are thought to soften the plant cell wall to facilitate migration within the plant. Knock-down of a pectate lyase gene by RNAi in H. schachtii J2 resulted in fewer infections (Vanholme et al., 2007), and transient expression of a $G$. rostochiensis pectate lyase in Nicotiana benthamiana leaves resulted in severe malformations of the infiltrated tissues (Kudla et al., 2007), indicating an important role of pectate lyase in infection and parasitism of plants.

The presence of pectate lyase genes in the non-pathogenic nematode Bursaphelenchus mucronatus (Kikuchi et al., 2006) and in the fungivorous nematode Aphelenchus avenae (Karim et al., 2009) suggested that pectate lyase is more widely distributed among nematodes that have any association with plants than was previously thought. Recent phylogenetic analyses divided nematode sequences into three different clades, indicating different origins (Kikuchi et al., 2006; Kudla et al., 2007; Vanholme et al., 2007). Furthermore, the phylogenetic distribution of nematode pectate lyases based on available data does not match the expected phylogeny of nematode families (Kudla et al., 2007). This could imply that pectate lyases have several independent origins within plant-parasitic nematodes. However, it could also be a consequence of the fact that the number of homologues available is too small to yield robust phylogenies. The origin and evolution of the pectate lyases within nematodes will probably be clarified in the future when more sequence data becomes available.

\section{b) Polygalacturonase}

Polygalacturonases catalyze the hydrolysis of the pectic polygalacturonic acid and release oligogalacturonides. These are classified into two classes according to their mode of action: endo-polygalacturonases and exo-polygalacturonases (Jaubert et al., 2002). Nematode polygalacturonase identified from Meloidogyne incognita was predicted to be an exo-type belonging to GH28 based on similarity in the amino acid sequence (Jaubert et al., 2002). Polygalacturonase-like sequences have been identified in expressed sequence tag (EST) data for other Meloidogyne species, including M. javanica, M. arenaria, M. hapla, M. and $M$. chitwoodi, but not in other nematode ESTs, indicating a limited distribution of the gene in 
nematodes. Similarly to pectate lyases, the polygalacturonases are likely produced in the esophageal gland cells and secreted from the stylet of the nematode into plant tissue to facilitate the penetration and intercellular migration of the nematode (Jaubert et al., 2002).

c) Arabinogalactan endo-1,4- $\beta$-galactosidase and arabinase

Recently a new type of cell wall degrading enzyme was identified in cyst nematodes, namely a putative arabinogalactan endo-1,4- $\beta$-galactosidase belonging to GHF53 (EC 3.2.1.89) (Vanholme et al., 2009). Although activity assays on this enzyme are lacking, it is thought to hydrolyse $\beta$-1,4-galactan in the hairy regions of pectin. This would make the pectin backbone more accessible for pectate lyases. Searches through nematode ESTs and the Meloidogyne genomes failed to identify similar enzymes in other nematode species besides cyst nematodes. In the genome of $M$. incognita however, two predicted proteins show homology to GH43 arabinases (Abad et al., 2008). These proteins possibly hydrolyse the $\alpha$-1,5-linkages of arabinan polysaccharides, which are present as side chains of pectin. This suggests that the arabinases could have a similar role for root-knot nematodes as the galactosidase enzymes have for cyst nematodes (Vanholme et al., 2009).

\section{3) Non-enzymatic modification of plant cell walls}

A number of the known phytoparasitic nematode cell wall-modifying proteins with nonhydrolytic activity have a CBM predicted to bind to cellulose (see Davis et al., 2009; Kyndt et al., 2008; Mitchum et al., 2007). The cellulose-binding domain was a unique feature of some of the first phytoparasitic nematode endoglucanases to be isolated (Smant et al., 1998), but soon afterwards, a $M$. incognita transcript was isolated that encoded a protein with a cellulose binding domain (CBP), a linker domain found in the endoglucanases, and a novel upstream peptide sequence without a predicted glycosyl hydrolase active site (Ding et al., 1998). The Mi-CBP was expressed exclusively within the nematode esophageal gland cells, was detected in nematode stylet secretions, and was confirmed to bind to a cellulose substrate (Ding et al., 1998). CBPs have since been identified from several phytoparasitic nematode species with the common features of a cellulose-binding domain and a signal peptide for secretion, but with variation in peptide sequence upstream of the cellulose binding domain (see Davis et al., 2009; Kikuchi et al., 2009; Kyndt et al., 2008; Mitchum et al., 2007). The predicted peptide sequence upstream of a cellulose-binding domain isolated from G. rostochiensis had similarity to the non-hydrolytic expansin proteins found in plants (Qin et al., 2004). Plant expansins soften cell walls by breaking noncovalent bonds between cell wall fibrils, allowing the sliding of fibrils past each other to promote enzyme access and cell wall growth and flexibility (Cosgrove 2000). Functional assays of the Gr-EXP1 protein in plant tissues confirmed its expansin-like activity (Qin et al., 2004), representing the first report of an expansin-like protein outside of the plant kingdom. More recently, EST analyses have identified putative expansin-like sequences in several phytoparasitic nematode species including both sedentary and migratory endoparasites (Abad et al., 2008; Haegeman et al., 2009b, 2010; Kikuchi et al., 2007, 2009; Opperman et al., 2008; Roze et al., 2008). The presence of expansin domains in the absence of a CBM has been reported in B. xylophilus and other phytoparasitic nematode species, providing evidence for hypotheses on the evolution of the expansin gene family in nematodes (Kikuchi et al., 2009).

Similar to the function of expansins, overexpression of a bacterial CBP in plants promoted an increase in plant cell elongation (Shpigel et al., 1998). For hydrolytic proteins and expansins, the cellulose-binding domain appears to facilitate accumulation of the active sites of the proteins on the surface of the insoluble complex carbohydrates of the plant cell wall. Yeast 
two-hybrid analysis of an $H$. schachtii CBP with an Arabidopsis root library identified a plant pectin methyl esterase (PME3) as a specific interacting plant protein (Hewezi et al., 2008). The nematode CBP and plant PME were confirmed to interact within the plant host, and expression of Hs-CBP in Arabidopsis concomitantly increased expression of PME3.

Overexpression of either Hs-CBP or PME3 in Arabidopsis caused an increase in root growth and increased infection by $H$. schachtii, whereas the opposite effects were observed in pme 3 mutants of Arabidopsis. The results suggested that secreted Hs-CBP directly interacts with plant PME to facilitate parasitic establishment of the nematode within the root, potentially through targeted alteration of plant cell walls within infection sites (Hewezi et al., 1998).

\section{4) Degradation of fungal cell walls}

Some reports have suggested that plant parasitism may have evolved, in part, from fungal feeding nematodes (Jones et al., 2005). In fact, some nematodes including B. xylophilus have the ability to prey on both plants and fungi, whereas others use either plants or fungi exclusively. Identifying genes specific to these nematodes and others shared between them will provide clues to help identify parasitism genes and to understand the evolution of plant parasitism in nematodes. Here, we describe fungal cell wall degrading enzymes in phytoparasitic nematodes. The fungal cell wall contains various polysaccharides, but its main components are beta-1,3-glucan and chitin (Peberdy, 1990).

a) $\underline{\text {-1,3-glucan }}$

B-1,3-glucanases are widely distributed among bacteria, fungi, and higher plants. $\beta-1,3-$ glucanases catalyse the hydrolysis of B-1,3-D-glucosidic linkages in B-1,3-D-glucan. This polymer is a major component of fungal cell walls (Peberdy, 1990). Nematode B-1,3glucanases have been identified from B. xylophilus and B. mucronatus (Kikuchi et al., 2005). Most Bursaphelenchus species feed solely on fungi, and all species rely on fungi as a food source at some stage in their life cycle. Only a few species, including B. xylophilus, have the ability to parasitize plants. The Bursaphelenchus $3-1,3$-glucanases showed high similarity to GH16 proteins from bacteria. Similar sequences were also identified from the fungivorous nematode A. avenae (Karim et al., 2009), whereas no sequence-sharing similarity with B-1,3glucanase has been found in other phytoparasitic nematodes. The B. xylophilus genes are expressed solely in the esophageal gland cells of the nematode, and the protein was found in the secretions from the nematode. Therefore, the enzyme likely weakens fungal cell walls to facilitate nematode feeding (Kikuchi et al., 2005).

\section{b) Chitin}

Chitinases cleave the beta-1,4-glycosidic bonds of chitin, a beta-1,4-linked polymer of Nacetylglucosamine. Chitin is the main component of the fungal cell wall (Peberdy, 1990). Bursaphelenchus xylophilus has several chitinase genes in its genome. Some of them belong to GH18 and have actual enzyme activity. They are expressed in the esophageal glands and are likely secreted from the stylet of the nematode (T. Kikuchi unpublished result). The EST dataset of the fungivorous nematode A. avenae includes a few chitinase-like sequences. In these fungivorous nematodes, chitinases may facilitate the penetration of the fungal cell wall, enabling the nematode to feed on the cell contents.

Obligate phytoparasitic nematodes, which do not feed on fungi, also have chitinase genes. $\mathrm{Hg}-\mathrm{CHI}-1$ from $H$. glycines is expressed specifically in its subventral glands and is likely secreted from the stylet (Gao et al., 2002b). Furthermore, expression was detected only in parasitic stages, implying that it functions in the parasitic process (Gao et al., 2002). However, 
as plants do not contain chitin, the role of the chitinase in $H$. glycines remains to be determined (Gao et al., 2002b).

Chitinases in nematodes may serve as antifungal defences for free-living species, be involved in eggshell degradation, or serve as effectors from fungivorous nematodes. The genome sequence of $M$. incognita revealed a radical reduction in chitinases and chitin-binding proteins in the species. $M$. incognita possessed only 15 enzymes that were potentially involved in chitin degradation and binding, whereas Caenorhabditis elegans has 96 such enzymes (Abad et al., 2008). The suggested reason for this reduction is that, as obligate phytoparasitic nematodes including $M$. incognita spend most of their life cycles within the host plants, they may benefit from plant barriers and are thus better protected against fungi (Abad et al., 2008).

\section{5) Evolutionary aspects of cell wall modifying proteins}

a) Introduction

Plant parasitism originated at least three times independently during nematode evolution: in the Tylenchomorpha, Triplonchida and Dorylaimida (Blaxter et al., 1998). Remarkably, it was recently proposed that endoparasitism within the Tylenchomorpha evolved at least ten times out of ectoparasitism: six times resulting in migratory endoparasitism and four times in sedentary endoparasitism (Holterman et al., 2009). Only in one case, (Meloidogyne spp.), sedentary endoparasitism appears to have evolved directly from migratory endoparasitism (Bert et al., 2008; Holterman et al., 2009). During evolution, plant-parasitic nematodes have adapted well to invade and parasitize their host by acquiring plant cell wall modifying proteins. The apparent separate evolutionary paths of different nematode species suggest that differences in the arsenal of parasitism genes probably exist between different nematodes with comparable lifestyles. An example of this difference is the presence of an arabinogalactan endo-1,4- $\beta$-galactosidase in cyst nematodes of the genus Heterodera, while the Meloidogyne genomes lack this enzyme (Vanholme et al., 2009). In contrast to root knot nematodes, no endoxylanases were found in cyst nematodes to date. However, endoglucanases in cyst nematodes were found to exhibit activity towards xylan, which could circumvent the apparent absence of xylanases (Gao et al., 2004b). A similar trend was observed in the genomes of plant pathogenic bacteria, where strikingly different numbers and combinations of genes encoding cell wall degrading enzymes occur (Van Sluys et al., 2002). These genus- or species-specific adaptations towards plant parasitism are essential to understand the evolution of plant parasitism.

\section{b) Evolutionary mechanisms}

Most cell wall-modifying enzymes exist in multigene families that originated through extensive gene duplication. Each copy of the gene can subsequently undergo functional specialization and evolve a specific expression pattern. For example, the expression pattern of the endoglucanases of Heterodera glycines and Radopholus similis revealed that some gene copies are expressed during early stages, while others are expressed exclusively in later stages (Gao et al., 2004a; Haegeman et al., 2008). Due to the relatively high amount of nematode sequence data for GHF5 endoglucanases, several hypotheses about the evolution of these genes have been put forward. A model proposed by Ledger et al. (2006) was adapted and extended by Kyndt et al. (2008). The evolution of the endoglucanases seems to reflect the species evolution: similar relationships between species have been found comparing rRNA genes. This apparent parallel gene and species evolution suggests that the ancestral endoglucanase emerged early in the evolution of Tylenchomorpha and that this ancestral endoglucanase must have included a CBM. The gene family extended already early during 
evolution, since some endoglucanases have an aberrant gene structure as a result from an early duplication event (Kyndt et al., 2008). Later during evolution, additional duplication events occurred and some gene copies have lost their CBM. The constantly ongoing evolution of endoglucanases is confirmed by the finding of several endoglucanase pseudogenes in Ditylenchus africanus (Haegeman et al., 2010).

In other genes, such as endoxylanase, a similar evolutionary pattern can be expected. Although this gene family is less extensive ( 6 copies in the $M$. incognita genome, while 21 copies for endoglucanase; Abad et al., 2008), duplication events also expanded this gene family. Since the introns of $M$. incognita and $R$. similis endoxylanases are in the same position, both most probably originated from a common ancestral endoxylanase (Haegeman et al., 2009a).

Additionally, it seems that genes can acquire domains from other genes through domain shuffling. Expansin-like genes of Ditylenchus africanus and Globodera rostochiensis for example possess a CBM that could be derived from endoglucanases by domain shuffling (Haegeman et al., 2010; Kudla et al., 2005). Moreover, cellulose binding proteins (CBPs) are similar to CBMs, and could have originated from endoglucanases by the loss of the catalytic domain (Ledger et al., 2006). These CBPs were shown to activate a plant pectin methylesterase, and are therefore thought to make the plant cell wall more accessible to cell wall degrading enzymes (Hewezi et al., 2008). This definitely illustrates the plasticity of the genes to adapt to the nematode's needs, and reflects the complexity of the evolution of these gene families.

c) Origin through horizontal gene transfer

One of the most remarkable findings concerning cell wall modifying proteins from phytoparasitic nematodes is that some of these are absent from all other nematodes and most other animals studied to date (Jones et al., 2005). Many of the corresponding genes resemble bacterial sequences, suggesting that these genes could have been acquired from bacterial plant pathogens through horizontal gene transfer (HGT). For example the nematode endo-1,4- $\beta$ glucanases from the Tylenchomorpha, which belong to GHF5, show very little similarity to eukaryote endoglucanases but are rather homologous to bacterial sequences. This has led to the conclusion that these genes were at some point in evolution acquired from bacteria, and later extensive gene duplication resulted in gene families. In animal-parasitic nematodes and insects, it was proven that genes derived from their bacterial symbiont Wolbachia are present and transcriptionally active in the genome of the nematode or insect (Dunning-Hotopp et al., 2007). Since a Wolbachia-like symbiont was recently discovered in a phytoparasitic nematode species as well (Haegeman et al., 2009c), ancestors of these symbionts could be the origin of some of the cell wall modifying proteins.

Remarkably, the GHF45 endoglucanases from Bursaphelenchus xylophilus show the highest homology to fungal sequences. Since Bursaphelenchus xylophilus is a facultative fungal feeder, it makes sense that this gene was acquired from fungi (Kikuchi et al., 2004).

Moreover, an endo-1,3- $\beta$-glucanase (GHF16) present in B. xylophilus and the fungal feeder $B$. mucronatus as well as in Aphelenchus avenae has sequence characteristics that suggest it was acquired by HGT from bacteria (Karim et al., 2009; Kikuchi et al., 2005). It is possible that these nematodes acquired endo-1,3- $\beta$-glucanase genes from bacteria to obtain a fungal feeding ability, and subsequently acquired cellulase genes from fungi, which permitted them to parasitize plants (Jones et al., 2005). 
However, the horizontal gene transfer hypothesis should be handled cautiously. The problem is that there are no strict objective rules about how to test whether a given gene was acquired from another non-related organism via HGT. The most commonly used - and in many cases the only - reason to claim that genes are of HGT origin is that no homologous genes can be found in other eukaryotes, only in bacteria or fungi (Mitreva et al., 2009). It will probably become more clear in the future when more sequence data will become available, although endogenous GHF5 and GHF45 endoglucanases have also been found in insects and molluscs (Girard and Jouanin, 1999; Lee et al., 2004; Sugimura et al., 2003; Xu et al., 2001). Moreover, a putative GHF5 endoglucanase was recently discovered in the free-living nematode Pristionchus pacificus, and was proposed to be a pre-adaptation towards plant parasitism (Dieterich et al., 2008). It should be noted that this putative GHF5 endoglucanase has a very low similarity to GHF5 endoglucanases from plant-parasitic nematodes, and specific functional tests for this putative enzyme are lacking. Therefore, no preliminary conclusions should be made about the possible presence of endoglucanases in free-living nematodes. Nevertheless, to determine if HGT actually is the case, a combination of methods should be proposed that together may lift the weaknesses of the individual approaches. For example, a combination of phylogenetic methods, analysis of the distribution pattern, and habitat overlap between inferred donor and recipient could be applied (Mitreva et al., 2009).

d) Cell wall modifying proteins and plant defense

Although cell wall modifying enzymes are of vital importance for the successful penetration and migration of nematodes through the plant cell wall, only a small part of the nematode transcriptome consists of cell wall modifying enzymes. This could be the result of a long coevolution between parasite and host. During evolution, it is likely that plants have learned to recognize nematode-produced cell wall modifying proteins, triggering early plant defense responses as a result. In oomycetes, CBMs may also act as an elicitor of defense responses in plants (Dumas et al., 2008). It is not yet clear if this is a general phenomenon of CBMs released by plant pathogens and to what extent nematode CBMs induce, either directly or indirectly through cell wall modifications, defense responses. Bacterial endoxylanases can likewise trigger plant defense systems (Belien et al., 2006). Moreover, nematode expansinlike proteins show significant similarity to putative avirulence proteins and pathogenicity factors, suggesting that expansin-like proteins may also be recognized by the plant. In the case of bacteria and fungi, the resulting defense responses can include the production of plant inhibitors of fungal and bacterial cell wall modifying enzymes, such as a polygalacturonase inhibiting protein or a xylanase inhibiting protein (Juge, 2006). Whether or not these or similar inhibitors are active against nematode cell wall modifying enzymes as well remains to be elucidated, but the high similarity of nematode enzymes to bacterial enzymes is an important indication that the nematode enzymes may also be targeted by the plant inhibitors. The delicate balance between nematode secreted proteins and plant defense responses has during evolution probably led to a careful and economic selection of secreted cell wall modifying proteins by the nematode.

\section{6) Concluding remarks}

The identification of endogenous genes encoding multiple types of cell wall-degrading enzymes in phytoparasitic nematodes has confirmed early physiological evidence for their expression and potential roles in plant parasitism (reviewed in Deubert and Rohde, 1971). Since the initial identification of endoglucanase genes in cyst nematodes (Smant et al., 1998), both a candidate gene approach and extensive EST analyses have been the primary means of gene identification. The relatively recent release of the genome sequence of two root-knot 
nematode species (Abad et al., 2008; Opperman et al., 2008) and other genome projects currently in progress are providing a more global view of the extent and organization of gene families encoding endogenous cell wall-modifying proteins in phytoparasitic nematodes. The genome sequences of both $M$. incognita and $M$. hapla have not only confirmed the presence of multiple cell wall-modifying genes that were found in expressed sequence analyses, but they have revealed how unexpectedly large some of these gene families are, most notably the genes encoding pectolytic enzymes and expansin-like proteins (Abad et al., 2008; Opperman et al., 2008). The genomic sequence of $M$. incognita (Abad et al., 2008) has identified some previously undiscovered glycohydrolase genes (GH32, GH43) in root-knot nematodes (or any metazoan), but it remains unclear if these genes play a role in plant parasitism or other physiological process within nematodes. The genomic organization of pectate lyase genes in M. hapla (Opperman et al., 2008) suggests a clustering and potential local expansion of this gene family within the genome, consistent with earlier reports of apparent endoglucanase gene duplication and inversion in the genome of cyst nematodes (Yan et al., 2001).

The existence of gene families that encode cell wall-modifying enzymes in nematodes presents the potential for functional redundancy, although the biological significance of this potential remains unclear. The partial reductions in nematode parasitic success observed using RNAi targeted to transcripts encoding nematode cell wall-degrading enzymes (Chen et al., 2005; Haegeman et al., 2009a; Rosso et al., 2005; Vanholme et al., 2007) suggest that such functional redundancy may be real, although the level of sequence complementarity and expression required for complete target gene silencing combined with technical challenges of the RNAi assays presents inherent difficulties in interpretation of the results. The reductions in parasitism observed in the RNAi experiments (Chen et al., 2005; Rosso et al., 2005), however, present convincing evidence that the secretion of cell wall-degrading enzymes plays a functional role in successful plant parasitism by nematodes. Expression of cell walldegrading enzymes in sedentary females of $M$. incognita (Rosso et al., 1999), perhaps to loosen plant tissues for egg-laying, and potential other functional roles of nematode cell wallmodifying enzymes may be realized upon further analyses. To date, however, the expression of nematode cell wall-modifying enzymes is almost exclusively localized within the esophageal gland secretory cells and developmentally consistent with the putative functional role of these secretions in migratory life stages of phytoparasitic nematodes.

One of the most significant themes arising from all of the current analyses of cell wallmodifying proteins in phytoparasitic nematodes is the mounting evidence to support the potential role of horizontal gene transfer (HGT) from microbes in the evolution of plant parasitism by nematodes (Davis et al., 2000; Dieterich and Sommer, 2009; Jones et al., 2005; Kyndt et al., 2008; Mitreva et al., 2009; Scholl et al., 2003; Wasmuth et al., 2008). An interesting observation is the apparent correlation of the type of endogenous nematode cell wall-modifying enzyme with the microbial community present in a given nematode ecological niche. The abundance of GH5 enzymes with similarity to genes present in bacteria found within the environment of soil-dwelling nematodes versus the presence of GH45 enzymes in B. xylophilus that are similar to those of the fungi found in its niche appears to have evolutionary relevance. Although the potential physical mechanisms of such proposed gene transfer remain elusive and difficult to definitively confirm, evidence for potential avenues of horizontal gene transfer of genes encoding cell wall-modifying enzymes is emerging. The recent discovery of a Wolbachia endosymbiont in R. similis (Haegeman et al., 2009c) presents such a potential for prokaryotic gene transfer and is supported by evidence from Wolbachia symbionts of other nematode and metazoan species (Hotopp et al., 2007). Caution not to overinterpret the role of HGT in evolution of parasitism is given by the monophyletic nature and apparent ancient eukaryotic origin of GH9 enzymes in a wide spectrum of metazoan taxa 
(Davison and Blaxter, 2005). Interestingly, GH9 enzymes were not identified within the Nematoda through this study (Davison and Blaxter, 2005), further suggesting an alternative, microbial origin of genes encoding cell wall-modifying enzymes in the evolution of plant parasitism by nematodes. 


\section{$\underline{\text { References }}$}

Abad, P., Gouzy, J., Aury, J.M., Castagnone-Sereno, P., Danchin, E.G.J., Deleury, E., PerfusBarbeoch, L., Anthouard, V., Artiguenave, F., Blok, V.C., Caillaud, M.C., Coutinho, P.M., Dasilva, C., De Luca, F., Deau, F., Esquibet, M., Flutre, T., Goldstone, J.V., Hamamouch, N., Hewezi, T., Jaillon, O., Jubin, C., Leonetti, P., Magliano, M., Maier, T.R., Markov, G.V., McVeigh, P., Pesole, G., Poulain, J., Robinson-Rechavi, M., Sallet, E., Segurens, B., Steinbach, D., Tytgat, T., Ugarte, E., van Ghelder, C., Veronico, P., Baum, T.J., Blaxter, M., Bleve-Zacheo, T., Davis, E.L., Ewbank, J.J., Favery, B., Grenier, E., Henrissat, B., Jones, J.T., Laudet, V., Maule, A.G., Quesneville, H., Rosso, M.N., Schiex, T., Smant, G., Weissenbach, J. and Wincker, P. (2008) Genome sequence of the metazoan plant-parasitic nematode Meloidogyne incognita. Nat. Biotechnol. 26:909-915.

Bacic, A., Harris, P.J. and Stone, B.A. (1988) Structure and function of plant cell wall. In The Biochemistry of Plants (Stumpf, P.K. and Conn, E.E., eds). New York: Academic Press, pp. 297-371.

Baldwin, J.G., Nadler, S.A., and Adams, B.J. (2004) Evolution of plant parasitism among nematodes. Annu. Rev. Phytopathol. 42:83-105.

Barras, F., Gijsegem, F.v., and Chatterjee, A.K. (1994). Extracellular enzymes and pathogenesis of soft-rot Erwinia. Annu Rev Phytopathol 32:201-234.

Belien, T., Van Campenhout, S., Robben, J. and Volckaert, G. (2006) Microbial endoxylanases: Effective weapons to breach the plant cell-wall barrier or, rather, triggers of plant defense systems? Mol. Plant. Microbe Interact. 19:1072-1081.

Bera-Maillet, C., Arthaud, L., Abad, P. and Rosso, M.N. (2000) Biochemical characterization of MI-ENG1, a family 5 endoglucanase secreted by the root-knot nematode Meloidogyne incognita. Eur. J. Biochem. 267:3255-3263.

Bert, W., Leliaert, F., Vierstraete, A.R., Vanfleteren, J.R. and Borgonie, G. (2008) Molecular phylogeny of the Tylenchina and evolution of the female gonoduct (Nematoda : Rhabditida). Mol. Phylogenet. Evol. 48:728-744.

Blaxter, M.L., De Ley, P., Garey, J.R., Liu, L.X., Scheldeman, P., Vierstraete, A., Vanfleteren, J.R., Mackey, L.Y., Dorris, M., Frisse, L.M., Vida, J.T. and Thomas, W.K. (1998) A molecular evolutionary framework for the phylum Nematoda. Nature 392:71-75.

Boraston, A.B., Bolam, D.N., Gilbert, H.J. and Davies, G.J. (2004) Carbohydrate-binding modules: fine-tuning polysaccharide recognition. Biochem. J. 382:769-781.

Carpita, N.C. and Gibeaut D.M. (1993). Structural models of primary cell walls in flowering plants-consistency of molecular structure with the physical properties of the wall during growth. Plant J. 3:1-30.

Cassab, G.I. 1998. Plant cell wall proteins. Annu. Rev. Plant Physiol. Plant Mol. Biol. 49:281309. 
Chen, Q., Rehman, S., Smant, G., Jones, J.T. (2005) Functional analysis of pathogenicity proteins of the potato cyst nematode Globodera rostochiensis using RNAi. Mol. PlantMicrobe Interact. 18:621-625.

Collins, T., Gerday, C. and Feller, G. (2005) Xylanases, xylanase families and extremophilic xylanases. FEMS Microbiol. Rev. 29:3-23.

Cosgrove, D.J. (2000) Loosening of plant cell walls by expansins. Nature 407:321-326.

Darley C.P., Forrester A.M., McQueen-Mason S.J. (2001) The molecular basis of plant cell wall extension. Plant Mol Biol 47:179-195.

Davis, E.L., Hussey, R.S., Baum, T.J., Bakker, J., Schots, A., Rosso, M.N., and Abad. P. (2000) Nematode parasitism genes. Annu. Rev. Phytopathol. 38:341-372.

Davis, E.L., Hussey, R.S., and Baum, T.J. (2009) Parasitism genes: what they reveal about parasitism. In Plant Cell Monographs: Cell Biology of Plant Nematode Interactions (Berg, R.H., and Taylor, C.G., eds.) Heidelberg: Springer, pp 15-44.

Davison, A., and Blaxter, M. (2005) Ancient origin of glycosyl hydrolase family 9 cellulase genes. Mol. Biol. Evol. 22:1273-1284.

De Boer, J.M., Smant, G., Goverse, A., Davis, E.L., Overmars, H.A., Pomp, H.R., Van Gent Pelzer, M., Zilverentant, J.F., Stokkermans, J., Hussey, R.S., Gommers, F.J., Bakker, J., and Schots, A. (1996) Secretory granule proteins from the subventral esophageal glands of the potato cyst nematode identified by monoclonal antibodies to a protein fraction from secondstage juveniles. Mol. Plant Microbe Interact. 9:39-46.

DeBoer, J.M., Yan, Y., Wang, X., Smant, G., Hussey, R.S., Davis, E.L., and Baum, T.J. (1999) Developmental expression of secretory beta-1,4-endoglucanases in the subventral esophageal glands of Heterodera glycines. Mol. Plant Microbe Interact. 12:663-669.

De Boer, J.M., McDermott, J.P., Davis, E.L., Hussey, R.S., Popeijus, H., Smant, G., and Baum, T.J. (2002). Cloning of a putative pectate lyase gene expressed in the subventral esophageal glands of Heterodera glycines. J Nematol 34:9-11.

De Ley, P. and Blaxter, M. (2002) Systematic position and phylogeny. In The Biology of Nematodes (Lee, D.L., ed). London: Taylor \& Francis, pp. 1-30.

Deubert, K.H., and Rohde, R.A. (1971) Nematode enzymes. In Plant Parasitic Nematodes, Vol. 2 (Zuckerman, B.M., Mai, W.F., and Rohde, R.A. (eds). New York: Academic Press, pp 73-90.

Dieterich, C., and Sommer, R. (2009) How to become a parasite - lessons from the genomes of nematodes. Trends Genet. 25:203-209.

Dieterich, C., Clifton, S.W., Schuster, L.N., Chinwalla, A., Delehaunty, K., Dinkelacker, I., Fulton, L., Fulton, R., Godfrey, J., Minx, P., Mitreva, M., Roeseler, W., Tian, H., Witte, H., Yang, S.P., Wilson, R.K. and Sommer, R.J. (2008) The Pristionchus pacificus genome provides a unique perspective on nematode lifestyle and parasitism. Nat. Genet. 40:11931198. 
Ding, X., Shields, J., Allen, R., Hussey, R.S. (1998) A secretory cellulose-binding protein cDNA cloned from the root-knot nematode (Meloidogyne incognita). Mol Plant-Microbe Interact. 11:952-959.

Doyle, E.A., and Lambert, K.N. (2002). Cloning and characterization of an esophageal-glandspecific pectate lyase from the root-knot nematode Meloidogyne javanica. Mol Plant-Microbe Interact 15:549-556.

Dumas, B., Bottin, A., Gaulin, E. and Esquerre-Tugaye, M.T. (2008) Cellulose-binding domains: cellulose associated-defensive sensing partners? Trends Plant Sci. 13:160-164.

Dunning-Hotopp, J.C., Clark, M.E., Oliveira, D.C.S.G., Foster, J.M., Fischer, P., Torres, M.C., Giebel, J.D., Kumar, N., Ishmael, N., Wang, S.L., Ingram, J., Nene, R.V., Shepard, J., Tomkins, J., Richards, S., Spiro, D.J., Ghedin, E., Slatko, B.E., Tettelin, H. and Werren, J.H. (2007) Widespread lateral gene transfer from intracellular bacteria to multicellular eukaryotes. Science 317:1753-1756

Gao, B., Allen, R., Maier, T., Davis, E.L., Baum, T.J. and Hussey, R.S. (2002a) Identification of a new beta-1,4-endoglucanase gene expressed in the esophageal subventral gland cells of Heterodera glycines. J. Nematol. 34:12-15.

Gao, B., Allen, R., Maier, T., McDermott, J., Davis, E., Baum, T., and Hussey, R. (2002b). Characterisation and developmental expression of a chitinase gene in Heterodera glycines. Int. J. Parasitol. 32:1293.

Gao, B.L., Allen, R., Davis, E.L., Baum, T.J. and Hussey, R.S. (2004a) Developmental expression and biochemical properties of a beta-1,4-endoglucanase family in the soybean cyst nematode, Heterodera glycines. Mol. Plant Pathol. 5:93-104.

Gao, B., Allen, R., Davis, E.L., Baum, T.J. and Hussey, R.S. (2004b) Molecular characterisation and developmental expression of a cellulose-binding protein gene in the soybean cyst nematode Heterodera glycines. Int. J. Parasitol. 34:1377-1383.

Girard, C. and Jouanin, L. (1999) Molecular cloning of cDNAs encoding a range of digestive enzymes from a phytophagous beetle, Phaedon cochleariae. Insect Biochem. Mol. Biol. 29:1129-1142.

Goellner, M., Smant, G., de Boer, J.M., Baum, T.J. and Davis, E.L. (2000) Isolation of beta1,4-endoglucanase genes from Globodera tabacum and their expression during parasitism. $J$. Nematol. 32:154-165.

Haegeman, A., Jacob, J., Vanholme, B., Kyndt, T. and Gheysen, G. (2008) A family of GHF5 endo-1,4-beta-glucanases in the migratory plant-parasitic nematode Radopholus similis. Plant Pathol. 57:581-590.

Haegeman, A., Vanholme, B. and Gheysen, G. (2009a) Characterization of a putative endoxylanase in the migratory plant-parasitic nematode Radopholus similis. Mol. Plant Pathol. 10:389-401.

Haegeman, A., Jacob, J., Vanholme, B., Kyndt, T. Mitreva, M., and Gheysen, G. (2009b) Expressed sequence tags of the peanut pod nematode Ditylenchus africanus: The first 
transcriptome analysis of an Anguinid nematode. Mol. Biochem. Parasitol. 167:32-40.

Haegeman, A., Vanholme, B., Jacob, J., Vandekerckhove, T.T.M., Claeys, M., Borgonie, G. and Gheysen, G. (2009c) An endosymbiotic bacterium in a plant-parasitic nematode: member of a new Wolbachia supergroup. Int. J. Parasitol. 39:1045-1054.

Haegeman, A., Kyndt, T. and Gheysen, G. (2010) The role of pseudo-endoglucanases in the evolution of nematode cell wall modifying proteins. J. Mol. Evol. -submitted.

Henrissat, B. and Bairoch, A. (1996) Updating the sequence-based classification of glycosyl hydrolases. Biochem. J. 316:695-696.

Hewezi, T., Howe, P., Maier, T.R., Hussey, R.S., Goellner Mitchum, M., Davis, E.L. and Baum, T.J. (2008) Cellulose binding protein from the parasitic nematode Heterodera schachtii interacts with Arabidopsis pectin methylesterase: Cooperative cell wall modification during parasitism. Plant Cell 20:3080-3093.

Holterman, M., Karssen, G., van den Elsen S., van Megen H., Bakker, J. and Helder, J. (2009) Small subunit rDNA-based phylogeny of the Tylenchida sheds light on relationships among some high-impact plant-parasitic nematodes and the evolution of plant feeding.

Phytopathology 99:227-235.

Hotopp, J.C., Clark, M.E., Oliveira, D.C., Foster, J.M., Fischer, P., Torres, M.C., Giebel, J.D., Kumar, N., Ishmael, N., Wang, S., Ingram, J., Nene, R.V., Shepard, J., Tomkins, J., Richards, S., Spiro, D.J., Ghedin, E., Slatko, B.E., Tettelin, H., and Werren, J.H. (2007) Widespread lateral gene transfer from intracellular bacteria to multicellular eukaryotes. Science 317:17531756.

Huang, G., Dong, R., Allen, R., Davis, E.L., Baum, T.J., and Hussey, R.S. (2005).

Developmental expression and molecular analysis of two Meloidogyne incognita pectate lyase genes. Int J Parasitol 35:685-692.

Hussey, R.S. (1989) Disease-inducing secretions of plant-parasitic nematodes. Annu Rev Phytopathol 27:123-141.

Jaubert, S., Laffaire, J.B., Abad, P., and Rosso, M.N. (2002). A polygalacturonase of animal origin isolated from the root- knot nematode Meloidogyne incognita. FEBS Lett 522:109-112.

Jones, J.T., Furlanetto, C. and Kikuchi, T. (2005) Horizontal gene transfer from bacteria and fungi as a driving force in the evolution of plant parasitism in nematodes. Nematology 7:641646.

Jones, J.T., Moens, M., Mota, M., Li, H., and Kikuchi, T. (2008) Bursaphelenchus xylophilus: opportunities in comparative genomics and molecular host-parasite interactions. Mol. Plant Pathol. 9:357-368.

Juge, N. (2006) Plant protein inhibitors of cell wall degrading enzymes. Trends Plant Sci. 11:359-367. 
Karim, N., Jones, J.T., Okada, H. and Kikuchi, T. (2009) Analysis of expressed sequence tags and identification of genes encoding cell-wall-degrading enzymes from the fungivorous nematode Aphelenchus avenae. BMC Genomics 10:525.

Keen, N.T., and Roberts, P.A. (1998) Plant parasitic nematodes: digesting a page from the microbe book. Proc. Natl. Acad. Sci. (USA) 95:4789-4790.

Kikuchi, T., Jones, J.T., Aikawa, T., Kosaka, H. and Ogura, N. (2004) A family of glycosyl hydrolase family 45 cellulases from the pine wood nematode Bursaphelenchus xylophilus. FEBS Lett. 572:201-205.

Kikuchi, T., Shibuya, H. and Jones, J.T. (2005) Molecular and biochemical characterization of an endo-beta-1,3-glucanase from the pinewood nematode Bursaphelenchus xylophilus acquired by horizontal gene transfer from bacteria. Biochem. J. 389:117-125.

Kikuchi, T., Shibuya, H., Aikawa, T., and Jones, J.T. (2006). Cloning and characterization of pectate lyases expressed in the esophageal gland of the pine wood nematode Bursaphelenchus xylophilus. Mol Plant-Microbe Interact 19:280-287.

Kikuchi, T., Aikawa, T., Kosaka, H., Pritchard, L., Ogura, N. and Jones, J.T. (2007) EST analysis of the pine wood nematode Bursaphelenchus xylophilus and B. mucronatus. Mol. Biochem. Parasitol. 155:9-17.

Kikuchi, T., Li, H., Karim, N., Kennedy, M.W., Moens, M., and Jones, J.T. (2009) Identification of putative expansin-like genes from the pine wood nematode, Bursaphelenchus xylophilus, and evolution of the expansin gene family within the Nematoda. Nematology 11:355-364.

Kudla, U., Qin, L., Milac, A., Kielak, A., Maissen, C., Overmars, H., Popeijus, H., Roze, E., Petrescu, A., Smant, G., Bakker, J. and Helder, J. (2005) Origin, distribution and 3Dmodeling of Gr-EXPB1, an expansin from the potato cyst nematode Globodera rostochiensis. FEBS Lett. 579:2451-2457.

Kudla, U., Milac, A.L., Qin, L., Overmars, H., Roze, E., Holterman, M., Petrescu, A.J., Goverse, A., Bakker, J., and Helder, J. (2007). Structural and functional characterization of a novel, host penetration-related pectate lyase from the potato cyst nematode Globodera rostochiensis. Mol Plant Pathol 8:293-305.

Kyndt, T., Haegeman, A. and Gheysen, G. (2008) Evolution of GHF5 endoglucanase gene structure in plant-parasitic nematodes: no evidence for an early domain shuffling event. $B M C$ Evol. Biol. 8:305.

Ledger, T.N., Jaubert, S., Bosselut, N., Abad, P. and Rosso, M.N. (2006) Characterization of a new beta-1,4-endoglucanase gene from the root-knot nematode Meloidogyne incognita and evolutionary scheme for phytonematode family 5 glycosyl hydrolases. Gene 382:121-128.

Lee, S.J., Kim, S.R., Yoon, H.J., Kim, I., Lee, K.S., Je, Y.H., Lee, S.M., Seo, S.J., Sohn, H.D. and Jin, B.R. (2004) cDNA cloning, expression, and enzymatic activity of a cellulase from the mulberry longicorn beetle, Apriona germari. Comp. Biochem. Physiol. B. Biochem. Mol. Biol. 139:107-116. 
Lietzke, S.E., Yoder, M.D., Keen, N.T., and Jurnak, F. (1994). The Three-Dimensional Structure of Pectate Lyase E, a Plant Virulence Factor from Erwinia chrysanthemi. Plant Physiol 106:849-862.

Mitchum, M.G., Hussey, R.S., Davis, E.L., and Baum, T.J. (2007) Application of biotechnology to understand pathogenesis of nematode plant pathogens. In Biotechnology \& plant disease management (Punja, Z.K., DeBoer, S., and Sanfacon, H., eds)., Oxford, UK: CABI International, pp. 58-86.

Mitreva-Dautova, M., Roze, E., Overmars, H., de Graaff, L., Schots, A., Helder, J., Goverse, A., Bakker, J. and Smant, G. (2006) A symbiont-independent endo-1,4-beta-xylanase from the plant-parasitic nematode Meloidogyne incognita. Mol. Plant. Microbe Interact. 19:521529.

Mitreva, M., Smant, G. and Helder, J. (2009) Role of horizontal gene transfer in the evolution of plant parasitism among nematodes. In Horizontal gene transfer - Genomes in flux (Gogarten, M.B., Gogarten, J.P. and Olendzenski, L.C., eds). New York, NY: Humana Press, pp. 517-535.

Opperman, C.H., Bird, D.M., Williamson, V.M., Rokhsar, D.S., Burke, M., Cohn, J., Cromer, J., Diener, S., Gajan, J., Graham, S., Houfek, T.D., Liu, Q., Mitros, T., Schaff, J., Schaffer, R., Scholl, E., Sosinski, B.R., Thomas, V.P. and Windham, E. (2008) Sequence and genetic map of Meloidogyne hapla: A compact nematode genome for plant parasitism. Proc. Natl. Acad. Sci. U. S. A. 105:14802-14807.

Peberdy, J.F. (1990). Fungal Cell Walls a Review. In Biochemistry of Cell Walls and Membranes in Fungi (P.J. Kuhn, A.P.J. Trinci, M.J. Jung, M.W. Goosey, and L.G. Copping, eds). New York: Springer-Verlag, pp. 5-30.

Popeijus, H., Overmars, H., Jones, J., Blok, V., Goverse, A., Helder, J., Schots, A., Bakker, J., and Smant, G. (2000). Degradation of plant cell walls by a nematode. Nature 406:36-37.

Qin L., Kudla, U., Roze, E.H.A., Goverse, A., Popeijus, H., Nieuwland, J., Overmars, H., Jones, J.T., Schots, A., Smant, G., Bakker, J., Helder, J. (2004) Plant degradation: A nematode expansin acting on plants. Nature 427:30-31.

Rehman, S., Butterbach, P., Popeijus, H., Overmars, H., Davis, E.L., Jones, J.T., Goverse, A., Bakker, J. and Smant, G. (2009) Identification and characterization of the most abundant cellulases in stylet secretions from Globodera rostochiensis. Phytopathology 99:194-202.

Rosso, M.N., Favery, B., Piotte, C., Arthaud, L., de Boer, J.M., Hussey, R.S., Bakker, J., Baum, T.J. and Abad, P. (1999) Isolation of a cDNA encoding a beta-1,4-endoglucanase in the root-knot nematode Meloidogyne incognita and expression analysis during plant parasitism. Mol. Plant. Microbe Interact. 12:585-591.

Rosso, M.N., Dubrana, M.P., Cimbolini, N., Jaubert, S., Abad, P. (2005) Application of RNA interference to root-knot nematode genes encoding esophageal gland proteins. Mol. PlantMicrobe Interact. 18:615-620. 
Roze, E., Hanse, B., Mitreva, M., Vanholme, B., Bakker, J., Smant, G. (2008) Mining the secretome of the root-knot nematode Meloidogyne chitwoodi for candidate parasitism genes. Mol Plant Pathol 9:1-10.

Scholl, E.H., Thorne, J.L., McCarter, J.P., and Bird, D.M. (2003) Horizontally transferred genes in plant parasitic nematodes: a high-throughput genomic approach. Genome Biol. 4: R39.

Shibuya, H. and Kikuchi, T. (2008) Purification and characterization of recombinant endoglucanases from the pine wood nematode Bursaphelenchus xylophilus. Bioscience Biotechnology and Biochemistry 72:1325-1332.

Shpigel, E., Roiz, L., Goren, R., and Shoseyov, O. (1998) Bacterial cellulose-binding domain modulates in vitro elongation of different plant cells. Plant Physiol. 117:1185-94.

Smant, G., Stokkermans, J.P.W.G., Yan, Y.T., de Boer, J.M., Baum, T.J., Wang, X.H., Hussey, R.S., Gommers, F.J., Henrissat, B., Davis, E.L., Helder, J., Schots, A. and Bakker, J. (1998) Endogenous cellulases in animals: Isolation of beta-1,4-endoglucanase genes from two species of plant-parasitic cyst nematodes. Proc. Natl. Acad. Sci. U. S. A. 95:4906-4911.

Somerville, C. (2006) Cellulose synthesis in higher plants. Annu. Rev. Cell Dev. Biol. 22:5378.

Sugimura, M., Watanabe, H., Lo, N. and Saito, H. (2003) Purification, characterization, cDNA cloning and nucleotide sequencing of a cellulase from the yellow-spotted longicorn beetle, Psacothea hilaris. Eur. J. Biochem. 270:3455-3460.

Tamaru, Y., and Doi, R.H. (2001). Pectate lyase A, an enzymatic subunit of the Clostridium cellulovorans cellulosome. Proc Natl Acad Sci U S A 98:4125-4129.

Taylor, N.G. (2008) Cellulose biosynthesis and deposition in higher plants. New Phytologist 178:239-252.

Uehara, T., Kushida, A. and Momota, Y. (2001) PCR-based cloning of two beta-1,4endoglucanases from the root-lesion nematode Pratylenchus penetrans. Nematology 3:335341 .

Vanholme, B., Van Thuyne, W., Vanhouteghem, K., De Meutter, J., Cannoot, B., and Gheysen, G. (2007). Molecular characterization and functional importance of pectate lyase secreted by the cyst nematode Heterodera schachtii. Mol. Plant Pathol. 8:267-278.

Vanholme, B., Haegeman, A., Jacob, J., Cannoot, B. and Gheysen, G. (2009) Arabinogalactan endo-1,4-beta-galactosidase: a putative plant cell wall-degrading enzyme of plant-parasitic nematodes. Nematology 11:739-747.

van Megen, H., van den Elsen S., Holterman, M., Karssen, G., Mooyman, P., Bongers, T., Holovachov, O., Bakker, J. and Helder, J. (2009) A phylogenetic tree of nematodes based on about 1,200 full length small subunit ribosomal DNA sequences. Nematology 11:927-950.

Van Sluys, M.A., Monteiro-Vitorello, C.B., Camargo, L.E.A., Menck, C.F.M., da Silva, A.C.R., Ferro, J.A., Oliveira, M.C., Setubal, J.C., Kitajima, J.P. and Simpson, A.J. (2002) 
Comparative genomic analysis of plant-associated bacteria. Annu. Rev. Phytopathol. 40:169189.

Wang, X., Meyers, D.M., Baum, T.J., Smant, G., Hussey, R.S., and Davis, E.L. (1999) In planta localization of a B-1,4-endoglucanse secreted by Heterodera glycines. Mol. Plant Microbe Interact. 12:64-67.

Wasmuth, J., Schmid, R., Hedley, A., and Blaxter, M. (2008) On the extent and origins of genic novelty in the phylum Nematoda. PLoS Negl. Trop. Dis. 2(7):e258.

doi:10.1371/journal.pntd.0000258.

Wyss, U. (1987) Video assessment of root cell responses to dorylaimid and tylenchid nematodes. In Vistas on Nematology (Veech, J.A., and Dickson, D.W., eds.) Hyattsville: Society of Nematologists, pp 211-220.

Wyss U., and Zunke, U. (1986) Observations on the behaviour of second stage juveniles of Heterodera schachtii inside host roots. Rev Nematol 9:153-165.

Wyss U., Grundler, F.M.W., and Munch, A. (1992) The parasitic behaviour of second stage juveniles of Meloidogyne incognita in roots of Arabidopsis thaliana. Nematologica 38:98111.

Xu, B.Z., Janson, J.C. and Sellos, D. (2001) Cloning and sequencing of a molluscan endobeta-1,4-glucanase gene from the blue mussel, Mytilus edulis. Eur. J. Biochem. 268:37183727.

Yan, Y.T., Smant, G., Stokkermans, J., Qin, L., Helder, J., Baum, T., Schots, A., and Davis, E. (1998) Genomic organization of four beta-1,4-endoglucanase genes in plant-parasitic cyst nematodes and its evolutionary implications. Gene 220:61-70.

Yan, Y.T., Smant, G., and Davis, E. (2001) Functional screening yields a new beta-1,4endoglucanase gene from Heterodera glycines that may be the product of recent gene duplication. Mol. Plant. Microbe Interact. 14:63-71. 